\section{Comparative study of foot and mouth disease in apparently healthy Awassi sheep using different diagnostic tests in Jordan}

\author{
Raida Karim Al-Rukibat, Wael Hananeh, \\ Haitham Athamneh \\ Department of Veterinary Pathology and \\ Public Health, Jordan University of \\ Science and Technology, Irbid, Jordan
}

\begin{abstract}
Foot-and-mouth disease (FMD) is an extremely contagious viral disease of clovenhoofed domesticated as well as wild animals and has a great potential for causing severe economic losses. Four hundred blood samples were collected randomly from different sheep flocks from august to September 2010 from northern region of Jordan. In the present study, we investigated the prevalence of FMD in apparently healthy Awassi sheep and compared the hematological changes of those infected animals with their normal uninfected counterparts. The prevalence of FMD was 3\%, $4.25 \%$ and $51 \%$ by using polymerase chain reaction (PCR), nested PCR and competitive ELISA, respectively. There was significant increase in packed cell volume and eosinophils percentage in FMD positive group by ELISA. There were no significant differences in the other hematological parameters examined. In general FMD is endemic and widely spread among apparently healthy Awassi sheep that affects the economical progress in Jordan and other countries. This needs an international intervention to stop and control this disease.
\end{abstract}

\section{Introduction}

Foot-and-mouth disease (FMD) is a highly contagious vesicular disease affecting more than 33 species of cloven-hoofed animals, including domestic animals such as cattle and swine, and wild animals such as buffalo and goats. ${ }^{1}$ The disease has been designated by the Office International des Epizooties, World Organization of Animal Health, as a serious disease that spreads rapidly and requires socioeconomic consideration. FMD outbreaks exert heavy economic losses due to loss of productivity, decline in product quality, the slaughter of millions of infected and in-contact susceptible animals, and trade embargos on animal products. ${ }^{2}$ The etiological agent of FMD is FMD virus (FMDV), which belongs to the genus Aphthovirus of the family Picornaviridae. ${ }^{3}$ There are seven distinguishable serological types, namely, 0, A, C, Asial, SAT1, SAT2, and SAT3, and more than 65 subtypes. ${ }^{2}$

Epidemiological observations indicate that FMD is predominantly transmitted by movement of infected animals. Eradication and control of the disease is based on restriction the movement of infected animal, good biosecurity and separation of carriers. 4 The literature is rich by the epidemiological studies on FMD, However to the best of our knowledge, there is no single report has addressed the hematological parameters in subclinically FMD infected Awassi sheep. Furthermore only a few reports were published concerned the hematological parameters in experimental or clinical cases of FMD in cattle. . $^{5-7}$

The goals of this current study were to investigate the prevalence of FMD in apparently healthy Awassi sheep using different diagnostic tests and to compare the hematological parameters associated with the seropositive animals for FMDV.

\section{Materials and Methods}

\section{Location ad study design}

The sample size was calculated to be 383 animals based on a $10 \%$ proposed prevalence, a confidence interval of $95 \%$ that was adjusted to the actual sheep population in northern Jordan.

\section{Sample collection and preparation}

A total of 400 blood samples were collected from different sheep flocks placed on different areas in northern of Jordan. Peripheral blood was aseptically obtained from jugular vein with and without anticoagulant (EDTA0.2M). For serum collection, blood was allowed to clot and serum were Isolated in 1.5 Eppendorf tubes and stored at $-20^{\circ} \mathrm{C}$ until used.

\section{Hematology}

The whole blood tubes were used to determine differential leukocyte count, white blood cell count, red blood cell count, hematocrit (PCV, \%) hemoglobin concentration and erythrocyte indices [mean corpuscular volume (MCV), mean corpuscular hemoglobin (MCH) and mean corpuscular hemoglobin concentration (MCHC)].

\section{Competitive enzyme linked \\ immunosorbant assays}

The test procedure, precautions and interpretation of results sections for this test kits were carried out and followed closely according to the
Correspondence: Raida Karim Al-Rukibat, Department of Veterinary Pathology and Public Health, Faculty of Veterinary Medicine, Jordan University of Science and Technology, PO Box 3030 , Irbid 22110, Jordan.

Tel.: +962.2720.1000 ex.22008 - Fax: +962.2720.1081. E-mail: ralrukib@just.edu.jo

Key words: Sheep; foot-and-mouth disease; hematology; subclinical; Jordan.

Acknowledgments: Financial support of this work was provided by the Deanship of Scientific Research, Jordan University of Science and Technology, Irbid 22110, Jordan.

Contributions: the authors contributed equally.

Conflict of interest: the authors declare that they have no conflict of interest.

Received for publication: 11 September 2014. Revision received: 3 November 2014.

Accepted for publication: 4 November 2014.

This work is licensed under a Creative Commons Attribution NonCommercial 3.0 License (CC BYNC 3.0).

(C) Copyright R. Karim Al-Rukibat et al., 2015 Licensee PAGEPress srl, Italy

Veterinary Science Development 2015; 5:5633 doi:10.4081/vsd.2015.5633

manufacture instructions using the AniGen FMD NSP Ab competitive ELISA kits (Bionote Inc, Korea). If the product shows positive result, it means that the animal was infected by FMDV in field. AniGen FMD NSP Ab Rapid/ELISA kits are not relevant with the serotypes.

\section{Viral RNA extraction}

Viral RNA extraction from whole blood (with EDTA) was performed using commercially available RNA extraction Kit (Promega, Fitchburg, USA). Maxime RT-PCR PreMix Kit (iNtrobiotechnology) was used to reverse transcript the extracted RNA to cDNA. Briefly $1 \mu \mathrm{L}$ of template RNA and $19 \mu \mathrm{L}$ distilled water were added into the Maxime RT PreMix tubes (which have a Random primer) to a total volume of $20 \mu \mathrm{L}$. Then the clear pellet within the tube was Dissolve by pipetting. After that cDNA synthesis reaction was performed as the following using PCR thermocycler (DNA synthesis at $45^{\circ} \mathrm{C}$ for $60 \mathrm{~min}$ and RTase inactivation step at $95^{\circ} \mathrm{C}$ for $5 \mathrm{~min}$.

\section{Polymerase chain reaction amplifi- cation of reverse transcribed RNA \\ For PCR amplification 2X PCR Master mix Solution (i-MAX II, Seoul, Korea) was used; 10 $\mu \mathrm{L}$ of PCR Master mix Solution, $2 \mu \mathrm{L}$ template}


DNA, $1 \mu \mathrm{L}$ specific forward and reverse primers, and $6 \mu \mathrm{L}$ distilled water were added into PCR tube. The samples then were moved to thermocycler to perform PCR. The forward and reverse primers were within the VP1 protein gene. The forward primer was ACAGACGTTGCATTCGTGCTTGAC (nucleotide position between 88-112), while the reverse one was ATACAACTCTGCCCGCTTCATCCT (nucleotide position between 264-288). After amplification, $10 \mu \mathrm{L}$ of the reaction mixture was electrophoresed on $1.5 \%$ along with a 100 bp ladder. Ethidium bromide was mixed with the gel before cooling, and bands were visualized by transillumination with UV light.

\section{Nested polymerase chain reaction technique}

The primer sequences were selected from the conserved genomic sequences of the viral RNA polymerase gene. The region (derived from the genome of strain 01 Kaufbeuren, Cterminus of NS protein $3 \mathrm{~A}$ to $\mathrm{N}$-terminus of polymerase 3D) exhibits little variation among FMDV serotypes and is ideal for amplification and detection of all seven serotypes. ${ }^{8}$ PCR (external) primers: $3 \mathrm{C} 1$ antisense 5'-CGC TCT TCC ACA TCT CTG GT-3' (nucleotide position 01 Kaufb.: 6329-6348) and 3A1 sense 5'-CCA CAA GCT GAA GGA CCC T-3' (nucleotide position 01 Kaufb.: 5450-5468). Nested-PCR (internal) primers: 3C3 antisense 5'-GGC CTC ACC AGA GAA AAT CA-3' (nucleotide position 01 Kaufb.: 6054-6073) and 3C5 sense primer 5'- TAG AGC CAT GAC AGA CAG TG-3' (nucleotide position 01 Kaufb.: 5851-5871). PCR Samples were amplified in a one-step RTPCR in a final volume of $25 \mu \mathrm{L}$ containing $5 \mu \mathrm{L}$ extracted RNA and $1 \mu \mathrm{L}$ of each external primer. One $\mu \mathrm{L}$ of the RT-PCR product was amplified by nested-PCR. For the second amplification, 3C 3 and 3C5 primers were used. Each reaction was analyzed by agarose gel electrophoresis.

\section{Results}

Complete Blood Count results for the FMD positive and negative samples were presented in Table 1.

There were significant increase in packed cell volume (PCV \%) and eosinophil percentage in FMD positive group. RBCs count, WBCs count, lymphocyte, neutrophil, monocyte, basophil, MCV, MCH, and MCHC had no significant difference between the FMD positive and negative group using ELISA.

\section{ELISA and real time-polymerase chain reaction results}

Out of 400 examined samples 204 (51\%) were positive by ELISA while in RT-PCR, 12 samples out of 400 were positive (3\%). These samples had a band size of 477 bp (Figure 1).

\section{Nested polymerase chain reaction results}

Out of 400 examined samples 17 samples have a band size of $222 \mathrm{bp}$ which indicated that these samples were positive using nested PCR method with a prevalence of $4.25 \%$ (Figure 2).

The number and percentages of positive samples using different diagnostic techniques were summarized in Table 2.

\section{Discussion}

There are three particular features of FMD which make rapid, sensitive and specific laboratory tests essential for diagnosis. Firstly, it is the most contagious disease of cloven-hoofed animals and hence has the potential for explosive spread in susceptible livestock populations. Secondly, it is acknowledged as the most serious constraint to international trade in livestock and animal products. Thirdly, other viruses produce symptoms which are clinically indistinguishable from FMD, necessitating laboratory investigation for a definitive diagnosis. ${ }^{9}$

The consequences of vaccination on this serological study are very minimal since sampling was performed at least 7 months after the last vaccination. In addition, the used FMD ELISA is claimed by the manufacturer as being able to differentiate between vaccinated and infected animals since this ELISA detect antibodies to the non-structural proteins of the FMDV. Antibody to non-structural proteins (NSP) of FMDV had been used to differentiate vaccinated from infected animal in the field.10-14 Previous study demonstrated that diagnostic sensitivity and specificity of the antigen enzyme-linked immunosorbent assay $\mathrm{Ag}$ ELISA was $87.7 \%$ and $100 \%$, respectively. These results demonstrate that Ag-ELISA detecting FMDV is an accurate method for taking rapid measurements at the site of a suspected footand-mouth disease outbreak in Asia before confirmation of the disease diagnosis in the laboratory, thereby offering the possibility of implementing control procedures more rapidly. 15 Other study demonstrated that $3 \mathrm{ABC}$ ELISA (C-ELISA) developed in Denmark was

Table 1. Mean and standard deviation (mean $\pm \mathrm{SD}$ ) of hematological parameter for positive and negative group according to ELISA.

\begin{tabular}{lcc}
\hline Parameters & FMID positive group & FMD negative group \\
$\mathrm{RBC} \times 10^{6}, \mu \mathrm{L}$ & $10.5 \pm 3$ & $10.3 \pm 2.6$ \\
$\mathrm{PCV}, \%$ & $29.1 \pm 5.5^{*}$ & $27.3 \pm 5.5$ \\
\hline $\mathrm{Hb}, \mathrm{g} / \mathrm{dL}$ & $9.4 \pm 7.3$ & $9.2 \pm 8.6$ \\
$\mathrm{MCV}, \mathrm{fl}$ & $29 \pm 7.2$ & $27.7 \pm 7.1$ \\
\hline $\mathrm{MCH}, \mathrm{pg}$ & $9.2 \pm 8.4$ & $8.9 \pm 9.8$ \\
$\mathrm{MCHC}, \mathrm{g} / \mathrm{dL}$ & $32.1 \pm 18.8$ & $33.3 \pm 22.1$ \\
\hline WBC $\times 103, \mu \mathrm{L}$ & $10.6 \pm 2.3$ & $11 \pm 2.3$ \\
Neutrophil, \% & $55.1 \pm 10$ & $54.1 \pm 9.1$ \\
\hline Lymphocyte, $\%$ & $35.4 \pm 9.7$ & $37.1 \pm 9.8$ \\
Monocyte, $\%$ & $6.9 \pm 3.8$ & $6.9 \pm 3.8$ \\
\hline Eosinophil, \% & $2.6 \pm 1.7^{*}$ & $1.4 \pm 1.4$ \\
Basophil, \% & $0.5 \pm 0.8$ & $0.7 \pm 0.8$
\end{tabular}

FMD, foot-and-mouth disease; RBC, red blood cell; PCV, packed cell volume; Hb, hemoglobin; MCV, mean corpuscular volume; $\mathrm{MCH}$, mean corpuscular hemoglobin; MCHC, mean corpuscular hemoglobin concentration; WBC, white blood cell. *Significant difference from negative group $(\mathrm{P}<0.05)$.

Table 2. Number and percentages of positive samples that were tested for foot-and-mouth disease according to the polymerase chain reaction, nested polymerase chain reaction and ELISA. Number of positive samples Percentage

\begin{tabular}{lcc} 
ELISA positive & 204 & 51 \\
RT-PCR positive & 12 & 3 \\
\hline Nested PCR positive & 17 & 4.25 \\
RT-PCR positive + ELISA positive & 11 & 2.75 \\
\hline Nested PCR positive and ELISA positive & 16 & 4 \\
RT-PCR positive and nested PCR positive & 12 & 3 \\
\hline
\end{tabular}




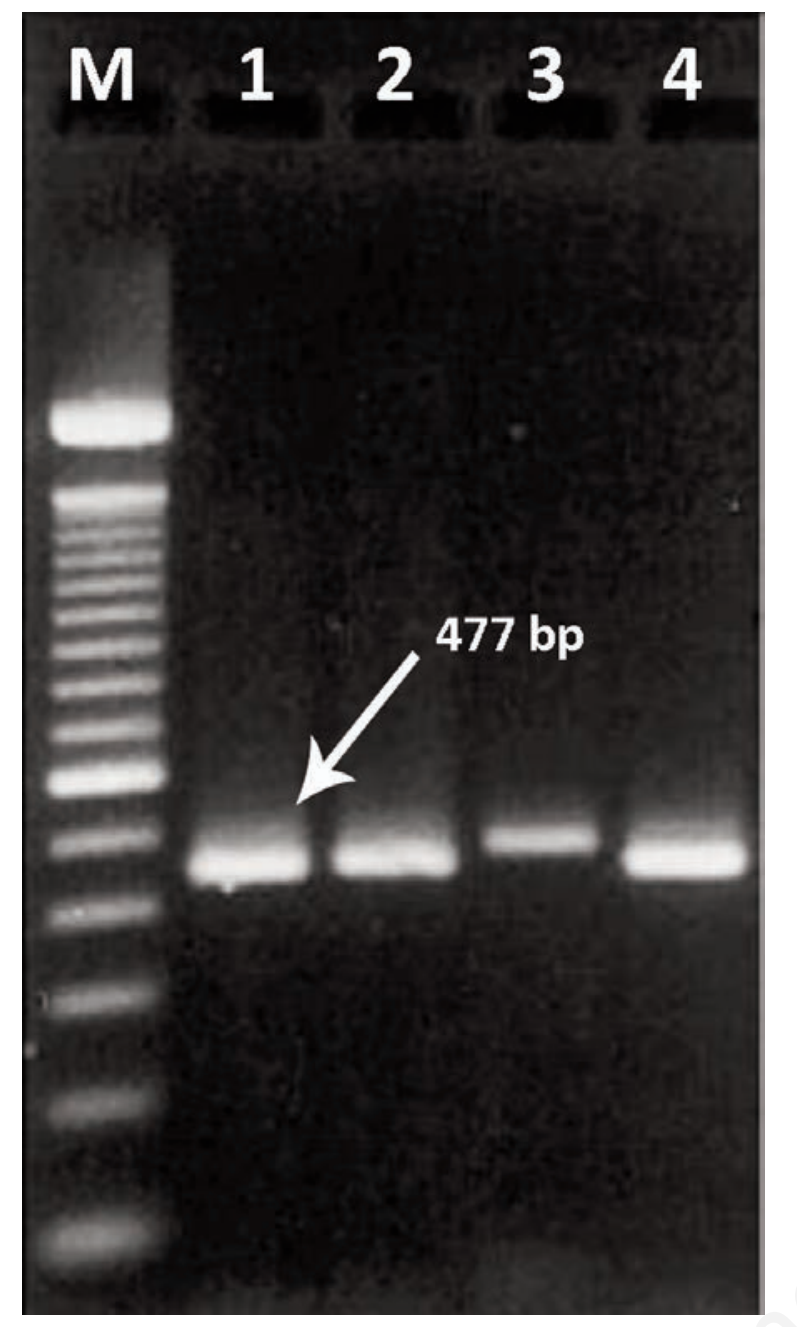

Figure 1. Real time-polymerase chain reaction results for detection of food-and-mouth disease virus in whole blood samples. Line 1-3: amplification of a $477 \mathrm{bp}$ DNA fragment in positive blood samples, line 4: positive control, M: DNA 100 bp ladder.

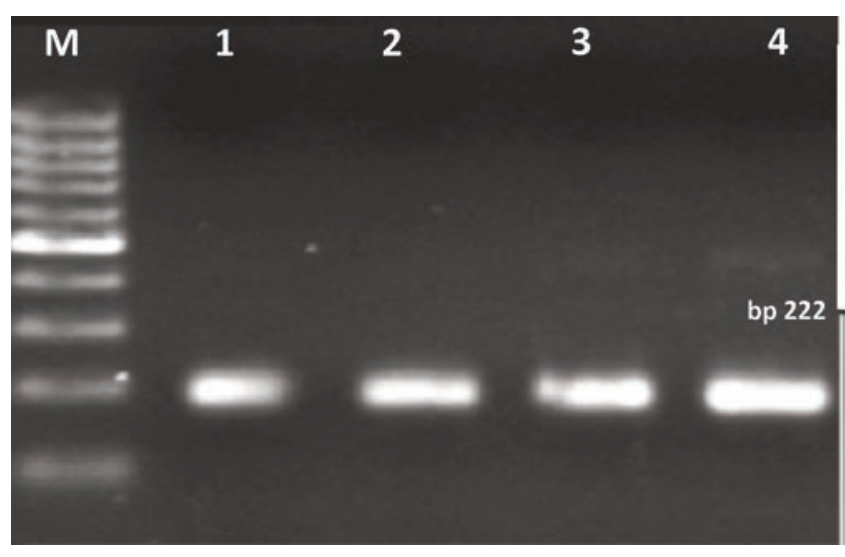

Figure 2. Nested polymerase chain reaction results for detection of food-and-mouth virus in whole blood samples. Line 1-4: amplification of a 222 bp DNA fragment in positive blood samples, line M: DNA 100 bp ladder.
$71 \%$ sensitive and $90 \%$ specific at the recommended cutoff. These results have important implications if the tests are to be used to screen herds or individual cattle in surveillance programs, at border crossings for importexport clearance, or following emergency vaccination in an outbreak situation. 16

In Jordan, Amareen et al. ${ }^{17}$ reported that the overall seroprevalence of FMD for sheep and goats varied with different NSP tests from 13\% to $30 \%$ and $73 \%$ to $94 \%$ in vaccinated and unvaccinated animals, respectively. Similarly, the overall seroprevalence for vaccinated cattle varied with different NSP tests from $30 \%$ to $82 \%$ with a tests specificity of $92 \%$ to $97 \%$.

The epidemiology and etiology of FMD have been extensively investigated.18,19 However, there are few published reports on the hematological and biochemical parameters of cattle with FMD. 5,6 However, those studies were carried out in the clinical cases of FMDV infection in bovine while this study was carried out in apparently health Awassi sheep. A significant reduction in the total number of RBCs and increase in MCV values with increased leukocytes counts in diseased group compared to their normal counterparts were found. ${ }^{6,7}$ Our study found a significant increase in packed cell volume (PCV \%) and eosinophil percentage within the positive ELISA results. RBCs count, WBCs count, lymphocyte, neutrophil, monocyte, basophil, MCV, MCH, and MCHC had no significant difference between the positive group and negative one. These results disagreed with the Egyptian study, in which they found that there were significant reductions in the total red blood cell count with increased leukocyte and lymphocytic counts in diseased group compared to control. 7

Carrier state is an important feature of FMD in ruminants. This may occur in non-vaccinated as well as in vaccinated ruminants following exposure to infectious FMD virus. Although the amount of infective virus that can be recovered from carriers is small, the virus can be present in some ruminants for months and in cattle for years. Previous study indicated that the frequency of FMD carriers among tested clinically normal cattle slaughtered in Abattoir was 34.59\% and this high frequency of carriers could be due to extensive FMDV circulation among susceptible animals. ${ }^{20}$ Our nested PCR results showed a low percentage (4.25\%) compared to the previous study where they used tonsil tissue samples for RNA extraction which contain more amount of RNA than that in blood samples. Generally tissue sample mostly contain more RNA amount than blood.

Twelve (3\%) blood samples were positive using PCR and Nested PCR methods. Blood sample number 344 shows negative result in ELISA but not in PCR and nested PCR. Hematological parameters for this sample was within the normal range; the OD value for this sample was 0.53 and PI value was $49 \%$, the 
result for this sample considered negative because the cut point was $50 \%$. Other explanation, it may be human or machinery errors.

Seventeen (4.25\%) samples were positive using nested PCR method. This indicates that nested PCR is more sensitive than normal one but less sensitive than ELISA. RT-PCR looks for antigen in blood, it might found but in small proportion, to have a good percentage the animal must be in a viremic phase in which the virus is established in the blood.

\section{Conclusions}

The described 3ABC-ELISA is safe, cheap and also easy to perform in large scale serological surveys. The high specificity and sensitivity makes this test an ideal tool for FMD eradication campaigns and control programs. As ELISA proved to be simple to perform, rapid and has high sensitivity, it will be very useful for FMD control and diagnosis in countries where disease needs to be confirmed as soon as possible in order to prevent spread and involvement of new areas.

Abnormally high or low hematological parameter may indicate the presence of many forms of disease, and hence hematology parameters are amongst the most commonly performed blood tests in medicine, as they can provide an overview of an animal's general health status. In FMD, hematological changes are of no relevance for the diagnosis of FMD, so it may be a need of further and concentrated studies pointed on FMD infected animal and there hematological parameter.

The low percentage of infection using either RT-PCR or Nested PCR was because FMD Virus is usually found in the blood during viremia and may be found several days prior to the onset of the clinical signs.

To the best of our knowledge this is the first report that gives some insights about the hematological parameters in apparently healthy subclinically FMD infected Awassi sheep.

\section{References}

1. Pereira HG. Foot-and-mouth disease. In: Gibbs EPJ, ed. Virus diseases of food animals. San Diego: Academic Press, Inc.; 1981. pp 333-363.

2. Yang PC, Chu RM, Chung WB, Sung HT. Epidemiological characteristics and financial costs of the 1997 foot-and-mouth disease epidemic in Taiwan. Vet Rec 1999;45:731-4.

3. Bachrach HL. Foot-and-mouth disease virus. Annu Rev Microbiol 1968;22:201-44

4. Thomson GR, Vosloo W, Bastos AD. Foot and mouth disease in wildlife. Virus Res 2003;91:145-61.

5. Mohan MS, Gajendragad MR, Kishore Subodh, et al. Experimental foot-andmouth disease in cattle and buffalo: haematological changes. Indian $\mathrm{J}$ Vet Path 2008;32:56-8.

6. Gürbüz G, Halil BG, Vehbi GH, Mehmet ÇTL. Alterations in some haematological and biochemical parameters in cattle suffering from foot- and -mouth disease. Turk J Vet Anim Sci 2004;28:723-7.

7. Ghanem MM, Abdel-Hamid OM. Clinical, haematological and biochemical alterations in heat intolerance (panting) syndrome in Egyptian cattle following natural foot-and-mouth disease (FMD). Trop Anim Health Prod 2010;42:1167-73.

8. Moss A, Hass B. Comparison of the plaque test and reverse transcription nested PCR for the detection of FMDV in nasal swabs and probang samples. J Virol Methods 1999;80:59-67.

9. Reid SM, Ferris NP, Hutchings GH, et al. Diagnosis of foot-and-mouth disease by RT-PCR: use of phylogenetic data to evaluate primers for the typing of viral RNA in clinical samples. Arch Virol 2001;146:242134.

10. Clavijo A, Wright $P$, Kitching. Developments in diagnostic techniques for differentiating infection from vaccination in foot-and-mouth disease. Vet $\mathrm{J}$ 2004;167:9-22.

11. Diego M, Brocchi E, Mackay D, De Simone F. The non-structural polyprotein $3 \mathrm{ABC}$ of foot-and-mouth disease virus as a diagnostic antigen in ELISA to differentiate infected from vaccinated cattle. Arch Virol 1997;142:2021-33.

12. Mackay DK, Forsyth MA, Davies PR, et al. Differentiating infection from vaccination in foot-and-mouth disease using a panel of recombinant, non-structural proteins in ELISA. Vaccine 1998;16:446-59.

13. Moonen P, van der Linde E, Chenard G, Dekker A. Comparable sensitivity and specificity in three commercially available ELISAs to differentiate between cattle infected with or vaccinated against footand-mouth disease virus. Vet Microbiol 2004;99:93-101.

14. Sorensen KJ, Madsen KG, Madsen ES, et al. Differentiation of infection from vaccination in foot-and-mouth disease by the detection of antibodies to the non-structural proteins $3 \mathrm{D}, 3 \mathrm{AB}$ and $3 \mathrm{ABC}$ in ELISA using antigens expressed in baculovirus. Arch Virol 1998;143:1461-76.

15. Oem JK, Ferris NP, Lee KN. Simple and rapid lateral-flow assay for the detection of foot-and-mouth disease virus. Clin Vaccine Immunol 2009;16:1660-4.

16. Bronsvoort KJ, Sørensen J, Anderson A, et al. Comparison of two 3ABC enzymelinked immunosorbent assays for diagnosis of multiple-serotype foot-and-mouth disease in a cattle population in an area of endemicity. J Clin Microbiol 2004;42:210814.

17. Amareen SP, Grainger L, Fleming M, et al. Sero-surveilance against foot and mouth disease virus (FMDV) nonstructural protien antibodies in sheep, goats and cattle in Jordan after 2006 Outbreak. Erice, Italy 14-17 October 2008.

18. Al-Majali AM, Jawasreh K, Al Nsour A. Epidemiological studies on foot and mouth disease and paratuberculosis in small ruminants in Tafelah and Ma'an, Jordan. Small Ruminant Res 2008;78:197-201.

19. Alexandersen S, Zhang Z, Donaldson AI. Aspects of the persistence of foot and mouth disease virus in animals the carrier problem. Microbes Infect 2002;4:1099-110.

20. Aliasghar B, Taghi T, Otfried M, et al. Application of nested-PCR for detection of foot-and-mouth disease viral sequences in tonsil of slaughtered cattle with clinically normal appearance in Iran. Veterinarski Arhiv 2007;77:299-306. 